Jurnal

Kardiologi Indonesia

J Kardiol Indones. 2015;36:138-44

ISSN $0126 / 3773$

Clinical Research

\title{
Prevalence, Characteristics, andRisk Factor of Patient with Peripartum Cardiomyopathyin Hasan Sadikin Hospital Bandung
}

\author{
Hawani Sasmaya Prameswari, Augustine Purnomowati, Toni M.Aprami
}

Department of Cardiology and Vascular Medicine, Faculty of Medicine, Padjadjaran University
Background. Peripartum cardiomyopathy (PPCM) is one of the important health problem and can be fatal. The aim of this study is to determine the prevalence and characteristics of patients with PPCM in the Hasan Sadikin Hospital (RSHS).

Methods. Data were retrieved retrospectively from medical records at the Cardiology and Vascular Medicine, RSHS, Bandung, from Ist]anuary20 I I to $3 I^{\text {th }}$ December, 20I3. The analysis was performed using SPSS 21 and Chi Square significance test.

Results.Eighty $(26.23 \%$,) subjects with PPCM out of 305 women with pregnancy or postpartum and cardiovascular complications are paticipated. The PPCMproportion are significantly decrease by time from $51.25 \%$, $27.5 \%, 21,25 \%$ in 2011 , 20I2, and 2013 respectively. The average age was $30.3 \pm 7.9$ years. Deliveries were cesarean delivery in $43.8 \%$, pervaginal in $37.5 \%$, forceps in $15 \%$, and vacuum-extractor in $3.8 \%$. Preeclampsia was found in $43.8 \%$ of patients and most of them with NYHA functional class IV (86.3The average ejection fraction of $34.8 \pm 7.5 \%$.

Conclusion. The prevalence of PPCM in RSHS is $26.23 \%$, with the majority (86.3\%) was NYHA functional class IV.Significant risk factorsof PPCM were age over 30 years, multiparous, low socioeconomic, and preeclampsia.

(J Kardiol Indones. 20I5;36: I38-44)

Keywords: peripartum cardiomyopathy, heart failure, pregnancy, postpartum 
Jurnal

\title{
Prevalensi, Karakteristik, dan Faktor Risiko Penderita Peripartum Cardiomyopathy di RS.Hasan Sadikin Bandung
}

\author{
Hawani Sasmaya Prameswari, Augustine Purnomowati, Toni M.Aprami
}

\begin{abstract}
Latar Belakang. Peripartum Cardiomyopathy (PPCM) merupakan salahsatu maslah kesehatn penting yang dapat berakibat fatal. Tujuan penelitian ini adalah mengetahui prevalensi dan karakteristik penderita PPCM di RS. Hasan Sadikin (RSHS).

Metode. Data diambil secara retrospektif dari catatan medik di bagian Kardiologi dan Kedokteran Vaskular RSHS Bandung periode 1 Januari 2011 hingga 31 Desember 2013. Analisis dilakukan dengan SPSS 21 dan uji kemaknaan chi square. Hasil. Didapatkan 80 penderita PPCM (26.23\%) dari total 305 penderita dengan komplikasi kardiovaskular selama kehamilan dan pascapersalinan. Sebaran menurun signifikan (p 0.002) yaitu 51.25\%, 27.5\%, dan 21.25\% pada tahun 2011, 2012 dan 2013 secara berurutan. Usia rata-rata penderita 30.3 7.9 tahun. Proses persalinan dengan operasi sesar (43.8\%), spontan pervaginam (37.5\%), forceps (15\%), dan vacum (3.8\%). Preeklampsi didapatkan pada $43.8 \%$ penderita dan mayoritas penderita termasuk NYHA kelas fungsional IV (86.3\%) dengan gambaran kardiomegali (96.25\%). Rerata fraksi ejeksi 34.8 $7.5 \%$. Kesimpulan. Prevalensi PPCM di RSHS 26.23\%, dengan sebagian besar penderita (86.3\%) termasuk dalam NYHA kelas fungsional IV. Beberapa faktor risiko yang signifikan adalah usia diatas 30 tahun, multipara, sosioekonomi rendah, dan hipertensi dalam kehamilan (preeklampsia).
\end{abstract}

(J Kardiol Indones. 2015;36:138-44)

Kata Kunci : peripartum cardiomyopathy, gagal jantung, kehamilan, pascapersalinan

\author{
Alamat Korespondensi \\ Dr. hawani sasmaya prameswari, PPDS Departemen Kardiologi \\ dan Kedokteran Vaskuler FK UNPAD*,Staf Pendidik Departemen \\ Kardiologi dan Kedokteran Vaskuler FK UNPAD** \\ Tel./E-mail: yogayun@yahoo.com
}




\section{Pendahuluan}

Peripartum Cardiomyopathy (PPCM) merupakan salah satu kardiomiopati dilatasi yang belum diketahui penyebabnya secara pasti. Insidensi di Amerika Serikat menunjukkan PPCM terjadi pada 1 dari 2500-4000 persalinan, dan Afrika selatan 1 dari 1000 persalinan. ${ }^{1,2}$

PPCM mempunyai beberapa definisi yang terus mengalami perkembangan. Definisi terbaru dari PPCM berdasarkan Heart Failure Association of the ESC Working Group tahun 2010, adalah kardiomiopati idiopatik yang ditandai dengan gagal jantung akibat sekunder dari disfungsi sistolik ventrikel kiri yang terjadi diakhir masa kehamilan atau beberapa bulan setelah persalinan. Penegakan diagnosis PPCM dilakukan dengan menyingkirkan diagnosis banding lainnya. Ekokardiografi merupakan salah satu pemeriksaan penunjang yang dapat membantu dalam penegakan diagnosis. Gambaran ekokardiografi penderita PPCM, umumnya menunjukkan dilatasi ventrikel kiri yang disertai global hipokinetik dan penurunan fraksi ejeksi. Beberapa literatur menyatakan hal yang berbeda, yaitu gambaran ventrikel kiri dapat saja tidak berdilatasi, namun disertai penurunan fraksi ejeksi mencapai kurang dari $45 \%$. $^{1,3,4,5}$

PPCM mempunyai berbagai faktor risiko, namun beberapa penelitian menyatakan faktor risiko yang sering timbul adalah usia, multipara, gemeli, hipertensi kronik, preeklamsia berat, eklampsia, dan ras hitam. ${ }^{1,4,6}$ Etiologi PPCM belum diketahui secara pasti, salah satu teori yang saat ini sering dikemukakan adalah hormon prolaktin yang berlebihan disertai dengan stres oksidatif yang tinggi pada ibu hamil sehingga dapat menimbulkan kerusakan sel-sel miokardium. ${ }^{17,8}$ PPCM berbeda dengan kardiomiopati lainnya. Fungsi jantung dapat kembali normal pada $23-41 \%$ penderita PPCM, sehingga perlu dilakukan deteksi dini, intervensi dan optimalisasi terapi untuk reversibilitas fungsi jantung. ${ }^{3,6,9}$
PPCM termasuk dalam kardiomiopati yang jarang terjadi dan penelitian yang terdokumentasi masih sangat sedikit. Tujuan dari penelitian ini adalah memberikan gambaran prevalensi, karakteristik, dan faktor risiko penderita PPCM di RSHS Bandung secara khusus, dan sebagai referensi untuk penelitianpenelitian selanjutnya secara umum.

\section{Metode Penelitian}

Penelitian ini dilakukan di Departemen Kardiologi dan Kedokteran Vaskular RSHS. Metode penelitian yang digunakan adalah retrospektif, deskriptif, dan analitik dengan subjek penelitian berupa data dari status rawat inap penderita di RSHS Bandung periode 1 Januari 2011 hingga 31 Desember 2013. Data selanjutnya dianalisis secara statistik dengan menggunakan SPSS 21 dan uji kemaknaan chi square 1 sampel pada beberapa variabel penelitian.

\section{Hasil Penelitian}

Hasil penelitian menunjukkan total penderita PPCM di RSHS Bandung periode 1 Januari 2011 hingga 31 Desember 2013, adalah 80 orang $(26.23 \%)$ dari total 305 penderita dengan komplikasi kardiovaskular selama kehamilan dan 6 bulan pascapersalinan. Pada penelitian ini didapatkan sebaran penderita PPCM di RSHS cenderung menunjukkan penurunan dari bulan Januari 2011 hingga Desember 2013. Berikut ini gambaran grafik sebaran jumlah penderita PPCM di RSHS Bandung periode 1 Januari 2011 hingga 31 Desember 2013.

Karakteristik penderita PPCM pada penelitian ini menunjukkan rata-rata usia penderita saat terdiagnosis PPCM adalah 30 tahun. Sebagian besar penderita (43.8\%) menjalani proses persalinan dengan operasi sesar. Data dari penelitian ini juga didapatkan 7 penderita PPCM (8.8\%) dengan gemeli. Parietas

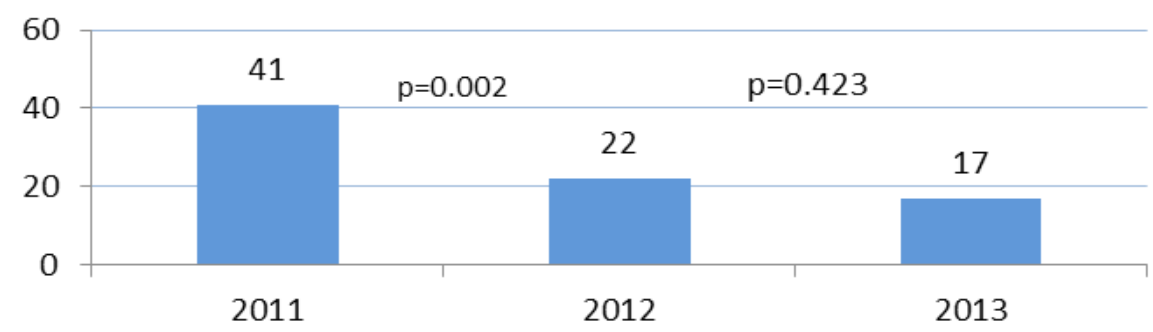

Gambar 1. Jumlah Penderita PPCM di RSHS 1Januari 2011- 31 Desember 2013 
penderita PPCM pada penelitian ini berbeda secara signifikan $(\mathrm{p}=0.020)$ dengan mayoritas penderita adalah multipara (42.5\%). Pada $82.5 \%$ penderita telah menjalani Prenatal Care (PNC) dengan cukup baik sesuai dengan ketentuan WHO, yaitu 4 kali selama masa kehamilan. Tingkat sosioekonomi penderita PPCM pada penelitian ini $46.3 \%$ berasal dari sosioekonomi rendah dengan penghasilan kurang dari 1 juta per bulan.

Hasil penelitian ini menunjukkan waktu penegakan diagnosis PPCM adalah 52.5\% pascapersalinan, dan $47.5 \%$ prapersalinan dengan perbedaan yang tidak signifikan ( $\mathrm{p}$ 0.502). Karakteristik klinik penderita PPCM pada penelitian ini beragam, dengan sebagian besar keluhan gagal jantung, yaitu $86.3 \%$ termasuk dalam NYHA kelas fungsional IV, dan 13.8\% termasuk NYHA kelas fungsional III. Hipertensi dalam kehamilan, yaitu preeklampsi didapatkan pada 35 penderita $(43.8 \%)$ sedangkan 28 penderita lainnya (35\%) tanpa hipertensi, dengan perbedaan yang signifikan $(\mathrm{p}<0.05)$.

Tabel 1. Data Karakteristik Umum Penderita PPCM di RSHS 1 Januari 2011- 31 Desember 2013

\begin{tabular}{|c|c|c|}
\hline Karakteristik & Nilai Statistik & $\mathrm{p}$ Value \\
\hline Usia & & 0.000 \\
\hline$<20$ thn & $6(7.5 \%)$ & \\
\hline $20-30$ thn & $6(45 \%)$ & \\
\hline$>30$ thn & $38(47.5 \%)$ & \\
\hline $\mathrm{X}(\mathrm{SB})$ & $30,3(7,9)$ & \\
\hline \multicolumn{3}{|l|}{ Proses Persalinan } \\
\hline Operasi sesar & $35(43,8 \%)$ & \\
\hline Spontan per Vaginam & $30(37,5 \%)$ & \\
\hline Forceps & $12(15 \%)$ & \\
\hline Vacum & $3(3,8 \%)$ & \\
\hline Gemeli & & 0.000 \\
\hline Tidak & $73(91,3 \%)$ & \\
\hline Gemeli & $7(8,8 \%)$ & \\
\hline \multicolumn{3}{|l|}{ Parietas } \\
\hline Primipara & $31(38.75 \%)$ & 0.020 \\
\hline Multipara & $34(42.5 \%)$ & \\
\hline Multigrandepara & $15(18.75 \%)$ & \\
\hline \multicolumn{3}{|l|}{ PNC } \\
\hline Kurang $(<4)$ & $14(17,5 \%)$ & \\
\hline Baik $(>4)$ & $66(82,5 \%)$ & \\
\hline Sosio Ekonomi & & 0.010 \\
\hline$<1$ juta & $37(46,3 \%)$ & \\
\hline $1-5$ juta & $28(35 \%)$ & \\
\hline$>5$ juta & $15(18,8 \%)$ & \\
\hline
\end{tabular}

Gejala gagal jantung yang dikeluhkan oleh penderita PPCM pada penelitian ini adalah 100\% DOE (Dyspneu on Effort), 95\% PND (Paroxysmal Nocturnal Dyspneu), dan $98.75 \%$ orthopnea. Hasil pemeriksaan fisik menunjukkan $96.25 \%$ penderita mengalami kardiomegali dengan tanda-tanda gagal jantung kiri kanan, sedangkan pada 3.75\% penderita ditemukan kardiomegali dengan tanda-tanda gagal jantung kiri saja. Berikut ini adalah data karakteristik klinik penderita PPCM di RSHS pada 1 Januari 2011 hingga 31 Desember 2013.

Tabel 2. Data Karakteristik Klinik Penderita PPCM di RSHS 1 Januari 2011- 31 Desember 2013

\begin{tabular}{lcc}
\hline Presentasi Klinis & $\mathrm{f}(\%)$ & $\mathrm{p}$-Value \\
\hline NYHA & $11(13,8 \%)$ & \\
$\quad$ III & $69(86,3 \%)$ & \\
IV & $28(35 \%)$ & \\
Tanpa Hipertensi & & \\
Hipertensi dalam Kehamilan & & \\
$\quad$ Preeklampsi & $13(16.0 .007$ \\
$\quad$ HT Gestasional & $2(2.5 \%)$ & \\
$\quad$ Eklampsi & $2(2,5 \%)$ & \\
HT Kronik &
\end{tabular}

Keterangan :Preeklampsia adalah tekanan darah sistolik (TDS) $\geq 140 \mathrm{mmHg} /$ diastolik $(\mathrm{TDD}) \geq 90 \mathrm{mmHg}$, proteinuria $(+)>20 \mathrm{mg}$ kehamilan; Eklampsia adalah disertai kejang; HT gestasional adalah kriteria diagnosis preeklampsi, proteinuria (-); HT kronik adalah TDS $\geq 140 \mathrm{mmHg} / \mathrm{TDD} \geq 90 \mathrm{mmHg}$ sebelum kehamilan atau $<20 \mathrm{mg}$ kehamilan. ${ }^{2}$

Tabel 3. Data Karakteristik Klinik Gejala dan Tanda Gagal Jantung dari Pemeriksaan Fisik pada Penderita PPCM di RSHS 1 Januari 2011- 31 Desember 2013

\begin{tabular}{ll}
\hline Gejala dan Tanda Gagal Jantung & $\mathrm{f}(\%)$ \\
\hline DOE & $80(100 \%)$ \\
PND & $76(95 \%)$ \\
Orthopnea & $79(98.75 \%)$ \\
Kardiomegali & $80(100 \%)$ \\
Takikardia & $76(95 \%)$ \\
S3 & $55(68.8 \%)$ \\
Ronkhi basah halus bilateral & $80(100 \%)$ \\
JVP/HJR & \\
-/- & $3(3.75 \%)$ \\
$+/+$ & $48(60 \%)$ \\
$+/$ sdn & $29(36.3 \%)$ \\
Edema Tungkai & $71(88.8 \%)$ \\
Murmur & \\
Tidak & $59(73,8 \%)$ \\
MR & $11(13,8 \%)$ \\
TR & $2(2,5 \%)$ \\
MR \& TR & $8(10 \%)$ \\
\hline
\end{tabular}


Penelitian ini juga menggambarkan hasil pemeriksaan penunjang penderita, EKG terbanyak yang didapatkan pada penelitian ini adalah sinus takikardia (91.3\%), dan poor $r$ wave progression due to DCM, LVH $(22.5 \%)$, sedangkan foto thoraks sebagian besar (91.25\%) menunjukkan gambaran kardiomegali dengan edema paru. Pemeriksaan penunjang lainnya yang ditampilkan dalam penelitian ini adalah ekokardiografi. Terdapat 22 penderita PPCM yang tidak dilakukan tindakan ekokardiografi selama perawatan. Gambaran ekokardiografi pada 58 penderita lainnya adalah $39.6 \%$ dilatasi seluruh ruang jantung, dengan $98.27 \%$ global hipokinetik, dan ratarata fraksi ejeksi adalah 34.8\%. Keseluruhan data fraksi ejeksi telah dilakukan uji normalitas distribusi data dengan tes Kolmogrov-smirnov dan didapatkan hasil distribusi data yang normal ( $\mathrm{p}>0.05)$.

Terapi pada penderita PPCM sesuai dengan pedoman penanganan dan terapi gagal jantung menurut ESC (European Society of Cardiology) 2012. Pada penelitian ini didapatkan 38 penderita terdiagnosis PPCM saat kehamilan, sehingga obatobat yang terdata berbeda dengan penderita yang terdiagnosis pascapersalinan. Berikut ini adalah tabel karakteristik terapi penderita PPCM.

Tabel 4. Karakteristik Pemeriksaan Penunjang Ekokardiografi pada Penderita PPCM di RSHS 1 Januari 2011-31 Desember 2013

\begin{tabular}{lc}
\hline Echocardiography & $\mathrm{f}(\%)$ \\
\hline Dilatasi Ruang Jantung & \\
Seluruh ruang jantung & $23(39.6 \%)$ \\
Atrium Kiri,Ventrikel Kiri & $20(34.48 \%)$ \\
Ventrikel Kiri & $15(25.86 \%)$ \\
Global hipokinetik & $57(98.27 \%)$ \\
EF(\%) & \\
Mean (Stdev) & $34,8(7,5)$ \\
Katup & \\
Trivial MR & $9(15.517 \%)$ \\
Trivial PR & $1(1.724 \%)$ \\
Trivial TR & $5(8.621 \%)$ \\
Mild AR & $5(8.621 \%)$ \\
Mild MR & $27(46.552 \%)$ \\
Mild PR & $3(5.172 \%)$ \\
Mild TR & $14(24.138 \%)$ \\
Moderate MR & $9(15.517 \%)$ \\
Moderate TR & $5(8.621 \%)$ \\
Severe MR & $2(3.448 \%)$ \\
\hline
\end{tabular}

Tabel 5. Karakteristik Terapi pada Penderita PPCM yang Terdiagnosis saat Kehamilan di RSHS 1 Januari 2011- 31 Desember 2013

\begin{tabular}{llll}
\hline & Terapi & $\mathrm{f}$ & $\%$ \\
\hline \multirow{4}{*}{ Pra Persalinan } & Furosemide & 38 & 100,0 \\
& Metildopa & 27 & 71,1 \\
& ISDN IV & 4 & 10,5 \\
& & & \\
Pasca Persalinan & Furosemide & 37 & 97,4 \\
& ACE Inhibitor & 30 & 78,9 \\
& Bisoprolol & 28 & 73.7 \\
& Metildopa & 25 & 65,8 \\
& Spironolacton & 2 & 5,3 \\
& Bromokriptin & 2 & 5,3 \\
\hline
\end{tabular}

Tabel 6. Karakteristik Terapi pada Penderita PPCM yang Terdiagnosis Pascapersalinan di RSHS 1 Januari 2011- 31 Desember 2013

\begin{tabular}{lcc}
\hline Terapi & $\mathrm{F}$ & $\%$ \\
\hline Furosemide & 42 & 100,0 \\
ACE Inhibitor & 36 & 85,7 \\
Bisoprolol & 27 & 64.3 \\
Spironolakton & 8 & 19.0 \\
Digoksin & 5 & 11.9 \\
Metildopa & 4 & 9,5 \\
Amlodipin & 3 & 7.1 \\
\hline
\end{tabular}

\section{Diskusi}

Angka kejadian PPCM masih sangat jarang, data penelitian salah satu rumah sakit di Asia Tenggara menunjukkan insidensi PPCM 0.89 dari 1000 persalinan. ${ }^{11}$ Pada penelitian ini didapatkan 80 penderita PPCM (26.23\%) dari total 305 penderita dengan komplikasi kardiovaskular selama kehamilan dan 6 bulan pascapersalinan di RSHS Bandung. Tampilan klinik penderita PPCM seringkali sulit terdeteksi, karena gejala-gejala gagal jantung yang menyerupai respon fisiologis kehamilan. ${ }^{12,13,14}$ Penelitian ini menunjukkan $86.3 \%$ penderita PPCM merupakan NYHA kelas fungsional IV. Data dari penelitian terdahulu sangat sedikit mengemukakan pemeriksaan fisik penderita PPCM. Pada penelitian ini didapatkan $96.25 \%$ penderita mengalami kardiomegali dengan tanda-tanda gagal jantung kiri kanan, sedangkan $3.75 \%$ penderita ditemukan kardiomegali dengan tanda-tanda gagal jantung kiri saja. Evaluasi terhadap gejala dan tanda gagal jantung sangat penting 
untuk dilakukan secara teliti, terutama pada penderita yang diduga mengalami PPCM. ${ }^{6,7,10}$

Diagnosis PPCM merupakan diagnosis per exclusionem, sehingga membutuhkan pemeriksaan penunjang (EKG,foto thoraks, dan ekokardiografi) untuk membantu menyingkirkan diagnosis banding lainnya. Pemeriksaan ekokardiografi merupakan pemeriksaan penunjang utama. ${ }^{6}$ Pada penelitian ini hasil ekokardiografi menunjukkan rata-rata fraksi ejeksi penderita adalah $34.8 \%$, dan $98.27 \%$ global hipokinetik, dengan 39.6\% dilatasi seluruh ruang jantung. Kelainan katup jantung yang sering ditemukan pada penelitian ini adalah mitral regurgitasi ringan.

Penanganan dan optimalisasi terapi berperan penting terhadap prognosis reversibilitas fungsi jantung penderita PPCM, yang sesuai dengan pedoman penanganan dan terapi gagal jantung ESC 2012..$^{2,15}$ Obat-obatan tertentu perlu disesuaikan pada penderita dalam kehamilan maupun menyusui, karena beberapa efek obat yang tidak baik untuk janin maupun bayi. Obat-obatan tersebut adalah golongan ACE inhibitor yang mempunyai efek toksisitas fetus yang tinggi, dan bagi ibu menyusui, karena efek obat yang keluar melalui ASI dapat menimbulkan efek samping hipotensi maupun kerusakan ginjal bagi neonatus dengan berat badan lahir rendah atau prematur. Obat golongan ACE-inhibitor yang sudah terbukti aman bagi ibu menyusui adalah captopril, enalapril, dan quinalapril. Alternatif pengobatan vasodilator lain untuk ibu hamil dan menyusui dapat diberikan metildopa, atau kombinasi golongan hidralazin dan nitrat. Golongan obat beta bloker yang sudah terbukti aman bagi ibu hamil adalah metoprolol, sedangkan bisoprolol dan carvedilol belum diketahui secara pasti, namun termasuk dalam kategori risiko C. ${ }^{4,16,17}$ Data penelitian ini menunjukkan terapi prapersalinan, penderita yang terdiagnosis saat kehamilan, berbeda dengan pascapersalinan, yaitu $71.1 \%$ mendapat metidopa dan $10.5 \%$ ISDN intravena. Penderita yang terdiganosis pascapersalinan, $85.7 \%$ mendapat ACE Inhibitor, $64.3 \%$ bisoprolol, dan 11.9\% digoksin. Bromokriptin merupakan obat baru dalam terapi PPCM yang berperan menghambat produksi prolaktin, namun obat tersebut masih harus melalui penelitian yang lebih besar untuk membuktikan efektifitasnya. ${ }^{18,19,20}$ Pada penelitian ini beberapa penderita telah mendapat bromokriptin, yaitu sebesar 5.3\%. Penanganan penderita PPCM harus dilakukan secara holistik, meliputi edukasi untuk kehamilan berikutnya dan alat kontrasepsi, karena risiko PPCM yang dapat timbul kembali. 5,20,21

PPCM dihubungkan dengan beberapa faktor risiko, yaitu ras, usia maternal, multipara, gemeli, hipertensi dalam kehamilan, sosioekonomi rendah, dan PNC yang tidak baik., ${ }^{6,1314}$ Pada penelitian ini didapatkan beberapa faktor risiko PPCM dengan hasil signifikan, yaitu usia, multipara, hipertensi dalam kehamilan, dan sosioekonomi rendah. Pada beberapa literatur usia penderita PPCM berkisar 16 hingga 44 tahun, dengan rata-rata 30 tahun. ${ }^{6,13}$ Data dari penelitian ini didapatkan rata-rata usia penderita adalah 30,3 tahun. Sebanyak $42.5 \%$ penderita PPCM pada penelitian ini adalah multipara. Data tersebut ditunjang oleh beberapa penelitian terdahulu yang menyatakan $71 \%$ penderita PPCM termasuk multipara. ${ }^{13,14,15}$ Pada penelitian ini hanya $8.8 \%$ penderita PPCM hamil gemeli, data ini serupa dengan beberapa penelitan lainnya yang menunjukkan 9-13\% penderita PPCM hamil gemeli. ${ }^{6,16}$ Pada Working Group Of Heart Failure ESC 2010, rentang waktu penegakan diagnosis PPCM adalah akhir masa kehamilan hingga beberapa bulan pascapersalinan, data tersebut menunjukkan diagnosis PPCM dapat timbul lebih dini, yaitu 17-36 minggu kehamilan., Pada penelitian ini sebagian besar penderita PPCM terdiagnosis pada pascapersalinan, terutama 1 bulan pascapersalinan, namun tidak berbeda secara signifikan dengan prapersalinan ( $\mathrm{p} 0.502$ ). Pada $82.5 \%$ penderita telah menjalani PNC dengan baik sesuai anjuran WHO. Penderita PPCM pada penelitian ini, $46.3 \%$ berasal dari sosioekonomi rendah, yang dikaitkan dengan malnutrisi sebagai salah satu faktor risiko timbulnya PPCM. ${ }^{15,17,18}$

PPCM seringkali dikaitkan dengan hipertensi dalam kehamilan, pada penelitian ini $43.8 \%$ penderita mengalami preeklampsi. Penelitian terdahulu menunjukkan hasil yang serupa, yaitu hipertensi dalam kehamilan terjadi pada $15-68 \%$ penderita PPCM di Amerika Serikat. ${ }^{7,18}$ Penelitian ini mempunyai keterbatasan, yaitu didapatkan 50 catatan medik penderita yang tidak lengkap dari total 305 . Penelitian lebih lanjut, baik deskriptif maupun analitik perlu dikembangkan untuk lebih mengetahui prevalensi, etiologi serta faktor-faktor risiko yang berperan dalam PPCM. Hal ini dapat menjadi dasar untuk meningkatkan kesadaran, khususnya tenaga kesehatan terhadap kejadian PPCM dengan harapan dapat menekan angka morbiditas maupun mortalitas ibu hamil dengan faktor-faktor risiko tersebut. 


\section{Kesimpulan}

PPCM merupakan penyakit yang masih jarang terjadi, pada penelitian ini didapatkan prevalensi PPCM 26.23\% dari total 305 penderita dengan komplikasi kardiovaskular selama kehamilan dan 6 bulan pascapersalinan. Tampilan klinik penderita pada penelitian ini menunjukkan $86.3 \%$ dengan NYHA kelas fungsional IV. Karakteristik pemeriksaan fisik didapatkan $3.75 \%$ penderita dengan kardiomegali disertai tanda gagal jantung kiri, dan 96.25\% kardiomegali dengan tanda gagal jantung kiri kanan. Pemeriksaan penunjang EKG menunjukkan $91.3 \%$ sinus takkikardia, dan foto thoraks $91.25 \%$ kardiomegali disertai edema paru. Hasil ekokardiografi yang melibatkan 58 penderita didapatkan hasil ratarata fraksi ejeksi 34.8 (7.5)\%, dengan $98.27 \%$ global hipokinetik, dan 39.6\% dilatasi seluruh ruang jantung. PPCM dihubungkan dengan beberapa faktor risiko, dan pada penelitian ini didapatkan faktor risiko PPCM yang signifikan, adalah usia diatas 30 tahun, multipara, hipertensi dalam kehamilan (preeklampsi), dan sosioekonomi rendah.

\section{Daftar Pustaka}

1. Sliwa K,Hilfiker-Kleiner D,Petrie MC,Mebazaa A,Pieske B,Buchmann E,et al.Current State of knowledge on aetiology,diagnosis, management, and therapy of peripartum cardiomyopathy: a position statement from the Heart Failure Association of the European Society of Cardiology Working Group on peripartum cardiomyopathy. Eur Heart J. 2010;12:767-78

2. Sarker HN, Dass BP. Peripartum cardiomyopathy. ORION. 2009;32:686-89.

3. Rmaraj K,Sorrel VL.Peripartum cardiomyopathy:Causes, diagn osis, and treatment.Cleve Clin J Med.2009;76(5):289-96.

4. MishraVN,MishraN,Devanshi.Peripartumcardiomyopathy. JAPI.2013;61:268-73

5. Aursulesei V,Datcu MD.Peripartum cardiomyopathy: A Systemic Review. Int J Cardiol. 2009;131(2):8-35.

6. Elkayam U.Clinical characteristics of peripartum cardiomyopathy in the United State. J Am Coll Cardiol. 2011;58(7):65970 .
7. Zagrosek VR,Lundqvist CB,Borghi C,Cifkova R,Ferreira R,Foidart JM,et al.Guidelines on the management of cardiovascular diseases during pregnancy. Eur Heart J. 2011;32:3147-97.

8. Joint National Comitte. The seventh report of the Joint Nationl Committe on prevention, detection, evaluation,treatment of high blood pressure.NIH.2004: 30-52.

9. Walenta K,Schwarz V,Schirmer SH,Kinderman I,Friedrich EB,Solomayer EF,et al.Circulating microparticles as indicators of peripartum cardiomyopathy.Eur Heart J.2012;33:1469-79.

10. Elkayam U,Mohammed W,Akhter,Singh H, Khan S, Bitar F,et al.Pregnancy-Associated Cardiomyopathy: Clinical characteristics and a comparison between early dan late presentation. Circulation.2005;111: 2050-55.

11. Sliwa K,Fett J,Elkayam U.Peripartum cardiomyopathy. Lancet.2006;368: 687-93.

12. Lim CP,Sim DK.Peripartum cardiomyopathy:experience in an Asian tertiary centre.Singapore Med J.2013;54(1):24-27.

13. Shah I,Hafizullah M,Shah TS,Faheem M,Rafiullah.Peripartum cardiomyopathy: risk factors, hospital course and prognosis;experiences at Lady Reading Hospital Peshawar. GARJPP.2012;1(1):1-11.

14. Johnson-Coyle L, Jensen L,Sobey A.Peripartum cardiomyopathy:Review and practice guidelines.Am J Crit Care Med.2012;21(2):89-97.

15. Goland S,Modi K,Bitar F,Janmohamed M,Mirocha JM,Czer L.Clinical profile and predictors of complications in peripartum cardiomyopathy.J Card Fail.2009;28(5):1-6.

16. Sliwa K,Blauwet L, Tibazarwa K,Smedema JP,Becker A,Mc Muray J,et al.Evaluation of bromocriptine in the treatment of acute severe peripartum cardiomyopathy: A proof of concept Pilot Study.Circulation.2010;121:1465-73.

17. Habedank D,Kuhnle Y,Elgeti T,Dudenhausen JW,Haverkamp W,Dietz R.Recovery from peripartum cardiomyopathy after treatment with bromocriptine.2008;10:1149-51.

18. Anderson JL,Horne BD.Birthing the genetics of peripartum cardiomyopathy .Circulation.2010;121:2157-59.

19. Shafiq M,Khan RA,Khan A,Shah A,Hussain S.Unrecognised peripartum cardiomyopathy will have dire consequences.Anest Pain Int Care.2013;17(2):195-7.

20. Hasan JA,Qureshi A,Ramejo BB,Kamran A.Peripartum cardiomyopathy characteristics and outcome in a tertiary care hospital.J Park Med Assoc.2010;60:377-80.

21. Shaikh S,ShaikhSA.Peripartum cardiomyopathy:Its frequency and maternal outcome.BJOG.2010;16(4):590-3. 